\author{
RESEARCH ARTICLE \\ 10.1029/2019JC015034 \\ Key Points: \\ - High-resolution observations and \\ numerical simulations of mesoscale \\ and submesoscale features at an \\ intense oceanic front \\ - Vertical velocities associated \\ with submesoscale features are \\ significantly higher than on the \\ mesoscale \\ - Downwelling submesoscale features \\ concentrate $80 \%$ of downward flux \\ of phytoplankton within $15 \%$ of the \\ surface area
}

Supporting Information:

- Supporting Information S1

Correspondence to:

S. Ruiz,

simon.ruiz@imedea.uib-csic.es

Citation:

Ruiz, S., Claret, M., Pascual, A., Olita, A., Troupin, C., Capet, A. et al. (2019). Effects of oceanic mesoscale and submesoscale frontal processes on the vertical transport of phytoplankton. Journal of Geophysical Research: Oceans, 124, 5999-6014. https://doi.org/10.1029/2019JC015034

Received 11 FEB 2019 Accepted 15 JUL 2019 Accepted article online 23 JUL 2019 Published online 23 AUG 2019

(C)2019. American Geophysical Union. All Rights Reserved.

\section{Effects of Oceanic Mesoscale and Submesoscale Frontal Processes on the Vertical Transport of Phytoplankton}

\author{
Simón Ruiz ${ }^{1}$ (D) Mariona Claret $^{2}$ (D), Ananda Pascual ${ }^{1}$ (D), Antonio Olita ${ }^{3}$ (D), \\ Charles Troupin ${ }^{4,5}$ iD, Arthur Capet ${ }^{6}{ }^{D}$, Antonio Tovar-Sánchez ${ }^{7}$ iD , John Allen ${ }^{4}$, \\ Pierre-Marie Poulain $^{8}$ (D), Joaquín Tintoré1,4 ${ }^{D}$, and Amala Mahadevan ${ }^{9}$ \\ ${ }^{1}$ Instituto Mediterráneo de Estudios Avanzados (CSIC-UIB), Esporles, Spain, ${ }^{2}$ Joint Institute for the Study of the \\ Atmosphere and Ocean, University of Washington, Seattle, WA, USA, ${ }^{3}$ Institute of Atmospheric Sciences and Climate, \\ CNR-ISAC, National Research Council, Cagliari Section, Cagliari, Italy, ${ }^{4}$ Balearic Islands Observing and Forecasting \\ System (SOCIB), Palma de Mallorca, Spain, ${ }^{5}$ Now at GeoHydrodynamics and Environment Research (GHER), \\ University of Liège, Liège, Belgium, ${ }^{6}$ Modelling for Aquatic Systems (MAST), University of Liège, Liège, Belgium, \\ ${ }^{7}$ Instituto de Ciencias Marinas de Andalucía (ICMAN-CSIC), Puerto Real, Spain, ${ }^{8}$ Istituto Nazionale di Oceanografia e \\ di Geofisica Sperimentale (OGS), Trieste, Italy, ${ }^{9}$ Woods Hole Oceanographic Institution, Woods Hole, MA, USA
}

\begin{abstract}
Oceanic fronts are dynamically active regions of the global ocean that support upwelling and downwelling with significant implications for phytoplankton production and export. However (on time scales $\gtrsim$ the inertial time scale), the vertical velocity is $10^{3}-10^{4}$ times weaker than the horizontal velocity and is difficult to observe directly. Using intensive field observations in conjunction with a process study ocean model, we examine vertical motion and its effect on phytoplankton fluxes at multiple spatial horizontal scales in an oligotrophic region in the Western Mediterranean Sea. The mesoscale ageostrophic vertical velocity ( $\sim 10 \mathrm{~m}$ /day) inferred from our observations shapes the large-scale phytoplankton distribution but does not explain the narrow (1-10 km wide) features of high chlorophyll content extending 40-60 m downward from the deep chlorophyll maximum. Using modeling, we show that downwelling submesoscale features concentrate $80 \%$ of the downward vertical flux of phytoplankton within just $15 \%$ of the horizontal area. These submesoscale spatial structures serve as conduits between the surface mixed layer and pycnocline and can contribute to exporting carbon from the sunlit surface layers to the ocean interior.
\end{abstract}

\section{Introduction}

Oceanic fronts are known to be hot spots for biological activity. They facilitate the vertical supply of nutrients for phytoplankton production (Lévy et al., 2001; Lévy, 2003; Mahadevan \& Archer, 2000; Rodríguez et al., 2001) and the subduction of organic matter and oxygen from the surface mixed layer to depth (Omand et al., 2015; Stukel et al., 2017). Spontaneous intensification of the lateral buoyancy gradient at a front strengthens its frontal jet and vorticity, which leads to ageostrophic dynamics and upwelling/downwelling (Thomas et al., 2008; McWilliams, 2016) at both mesoscale and submesoscales. Here the term mesoscale refers to oceanic structures $10-100 \mathrm{~km}$ in horizontal scale, characterized by Rossby number, Ro $\equiv U / f L \ll 1$ (where $U$ and $L$ are horizontal velocity and length scales, respectively, and $f$ is the Coriolis frequency), while submesoscale refers to features $1-10 \mathrm{~km}$ in horizontal extent with Ro $=\mathcal{O}(1)$ ).

Mesoscale eddies and fronts resulting from the baroclinic instability of lateral buoyancy gradients in the pycnocline generate frontogenesis that leads to vertical velocities of $\mathrm{O}(10 \mathrm{~m} /$ day $)$, which extend over the depth of the pycnocline (Allen et al., 2001). In the Western Mediterranean Sea, the quasi-geostrophic (QG) omega equation was used to estimate the $\mathrm{QG}$ vertical velocity $w_{\mathrm{QG}} \approx \pm 15 \mathrm{~m} /$ day (Gomis et al., 2001; Tintoré et al., 1991). Other studies have reported $w_{\mathrm{QG}}$ values of about $\pm 20 \mathrm{~m} /$ day in regions such as the Azores front (Rudnick, 1996), the Agulhas current (Nardelli, 2013), and Gulf Stream (Pascual et al., 2015). However, QG theory is valid for Rossby Number $\ll 1$. In scenarios (and at scales $\mathrm{O}(1-10 \mathrm{~km})$ ) where the relative vertical vorticity $(\zeta)$ is of the same order as the planetary vorticity $(f)$, this theory is inadequate, and other methods for diagnosing vertical motion need also be considered.

Several studies have shown the importance of submesoscale dynamics in generating much larger vertical velocities than mesoscale processes in frontal zones (Klein \& Lapeyre, 2009; Lapeyre \& Klein, 2006; 
Mahadevan \& Tandon, 2006; Sasaki et al., 2014). Frontogenesis in the surface mixed layer is intensified at the surface boundary (Thomas et al., 2008) and generates ageostrophic secondary circulations with $O(1) R o$, predominately cyclonic vorticity, and large vertical velocities that are particularly intensified in the downward direction. Recent work has shown that the submesoscale frontal ageostrophic secondary circulations, itself, contributes significantly to surface convergence, intensification of the front, and enhancement of the vertical velocity (Barkan et al., 2019; McWilliams et al., 2019). These three-dimensional submesocale structures can reach the base of the mixed layer or even cross it, depending on the stratification beneath the mixed layer. Both the weak upwelling/downwelling at mesoscales $(10-100 \mathrm{~km})$ and the more intense vertical motion at submesoscales (1-10 km) could greatly enhance vertical exchange across the stratified base of the mixed layer (Ramachandran et al., 2014). However, differences in spatial scales and regimes for mesoscale and submesoscale dynamics have made it challenging to identify their interaction (Capet et al., 2008).

While oceanic fronts are known to enhance the vertical exchange of nutrients, carbon, oxygen, and heat, the specific contributions of mesoscale and submesoscale dynamics to vertical transport are difficult to tease apart. Here we investigate the role of mesoscale and submesoscale vertical advection on biogeochemical properties by combining observations and modeling of an intense front in the Western Mediterranean Sea. Properties like oxygen, phytoplankton chlorophyll, and particulate organic carbon exhibit strong vertical gradients since they are altered by phytoplankton growth, which relies on sunlight and nutrients supplied from beneath. From examining the horizontal and vertical scales of anomalies in the distributions of oxygen and chlorophyll and using ship-based observations to estimate the mesoscale vertical velocities from the QG omega equation, we infer that the downward transport of oxygen and carbon in the observations is likely dominated by submesoscale processes. Using a numerical model that captures the dynamics of the front while resolving the submesoscale, we show that submesoscale dynamics generates narrow features of elevated oxygen and phytoplankton that are advected downward with vertical velocities that are at least twice as large as those inferred from the mesoscale analysis. These narrow features enable a fast export of organic matter below the photic depth and support the majority of the downward advective flux of organic matter over the simulated area.

The article is organized as follows: Section 2 describes the region and the observations used in this study, section 3 is devoted to the methods and model description, and section 4 presents results obtained through observational data analysis and a Process Study Ocean Model (PSOM). Concluding remarks are presented in section 5 .

\section{Observations}

\subsection{Region of Study: Western Mediterranean}

The Western Mediterranean is characterized by ubiquitous fronts between saltier Mediterranean water and fresher Atlantic water. In the Alboran Sea (Figure 1a), the general circulation is characterized by the presence of a quasi-permanent anticyclonic, western Alboran gyre and a more variable, anticyclonic eastern Alboran gyre (Renault et al., 2012). Further east, a third gyre can appear but is more sporadic. Associated with these gyres is a jet of Atlantic water whose salinity (36.2 at the Strait of Gibraltar, Gasser et al., 2017) changes as it progresses around the eddies and mixes with saltier resident surface Mediterranean Water (salinity > 37). The front between the distinct water masses (Gascard \& Richez, 1985) forms mesoscale meanders that evolve along with the vertical displacement of isopycnals within the pycnocline.

This oligotrophic region relies on the upwelling of nutrients for its phytoplankton productivity (Claustre et al., 1994; Estrada et al., 1993). As a consequence of the thermal stratification in spring and summer, the nutrient-depleted upper mixed layer cannot easily be resupplied with nutrients from the layers below. In this scenario, phytoplankton populations are mainly concentrated at the top of the nitracline and forms a Deep Chlorophyll Maximum (DCM) at about 40-60 m (e.g., Lavigne et al., 2015) where some light is available for photosynthesis. Previous studies on the variability of primary production within the DCM in oligotrophic areas of the ocean suggest that physical processes, such as instabilities and vertical exchange at fronts, underlie the observed enhancement of phytoplankton production (Ascani et al., 2013; Morán et al., 2001; Olita et al., 2017). Enhanced vertical motion at fronts can also lead to the downwelling of phytoplankton, increasing their export of organic carbon toward the ocean interior. 

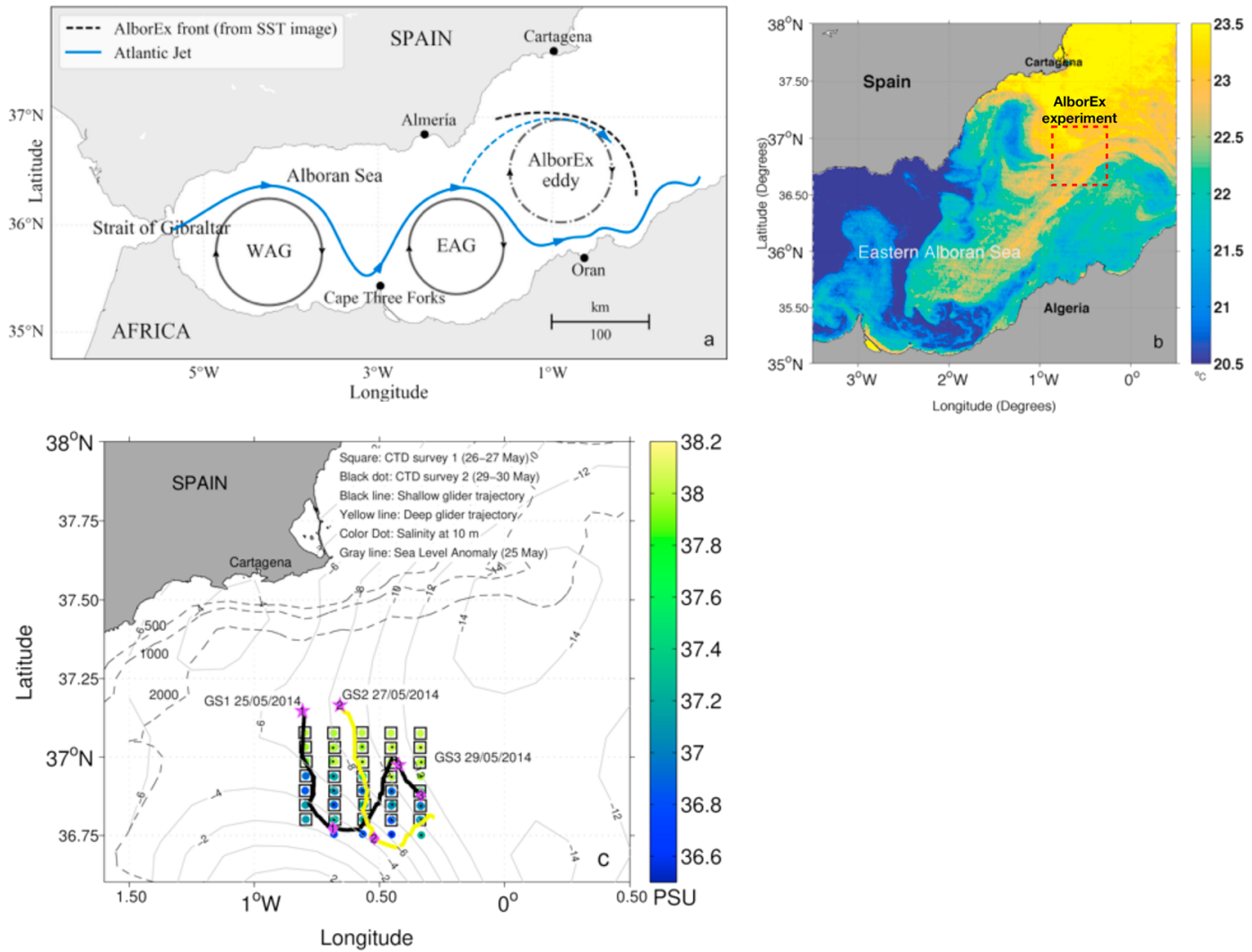

Figure 1. (a) Sketch of the general surface circulation of the Alboran Sea and (b) Sea Surface Temperature (Moderate Resolution Imaging Spectroradiometer-Aqua) for 28 May 2014. Red box indicates the study region in the Eastern Alboran Sea (Western Mediterranean) during the multiplatform AlborEx experiment (26-30 May 2014). (c) Squares and small black dots denote the positions of CTD casts for Surveys 1 and 2, respectively. Vessel Mounted-Acoustic Doppler Current Profiler measurements were collected between CTD stations. Black and yellow lines correspond to shallow and deep glider tracks, respectively. Tracks between stars and diamonds denote Glider Sections (GS): GS1 from 25 May 2014, 10:15 A.M. (Star 1) and 27 May 2014, 10:18 A.M. (Diamond 1); GS2 between 27 May 2014, 10:04 A.M. (Star 2) and 29 May 2014, 11:20 A.M. (Diamond 2); and GS3 29 May 2014, 11:15 A.M. (Star 3) and 29 May, 7:30pm (Diamond 3). In this study we use GS1 and GS2. Colored dots correspond to salinity at $10 \mathrm{~m}$ from CTD casts. Gray thin lines represent sea level anomaly from Archiving, Validation, and Interpretation of Satellite Oceanographic data for 25 May 2014. Isobaths of 500, 1,000, and 2,000 $\mathrm{m}$ are shown as dashed lines. Matlab 2012a (https://www.mathworks.com/) was used to create this figure. SST = Sea Surface Temperature; EAG = eastern Alboran gyre; WAG = western Alboran gyre; CTD = Conductivity-Temperature-Depth.

\subsection{AlborEx: A Multiplatform and Multidisciplinary Experiment}

In the late spring of 2014, a multiplatform and multidisciplinary research experiment, AlborEx, was conducted in the Eastern Alboran Sea during a period when a third gyre had formed to the east of the western Alboran gyre and eastern Alboran gyre (Figure 1b). The field campaign, carried out over 8 days, consisted of the deployment of 25 drifters, 2 gliders, and 3 Argo floats from the Research Vessel SOCIB, which procured 66 Conductivity-Temperature-Depth (CTD) casts and 500 biochemical samples (Ruiz et al., 2015; Troupin et al., 2019). Sea Surface Temperature at 1-km resolution (Level 2 product, available from NASA Ocean Color web, https://oceancolor.gsfc.nasa.gov/) and Sea Surface Height (SSH) at $1 / 8^{\circ}$ resolution from remote sensing (Level 4 product from Copernicus Marine Environment and Monitoring Service web, http://marine. copernicus.eu/services-portfolio/access-to-products/) provided an oceanographic context of the mesoscale and submesoscale scale features in the study area. Analysis of data from Argo floats, drifters, and the biochemical samples is described in Pascual et al. (2017) and Olita et al. (2017). Here we focus on findings from the ship CTDs, glider measurements, and Vessel Mounted-Acoustic Doppler Current Profiler (VM-ADCP) data, along with results from a numerical model simulation.

\subsection{CTD and VM-ADCP Data}

Two CTD surveys were performed over an area of about $40 \mathrm{~km} \times 40 \mathrm{~km}$ (Figure 1c). Survey 1 was carried out between 26 and 27 May 2014 and consisted of 34 casts along five north/south legs. The second survey was 
Table 1

Spatial and Temporal Resolution for Ship CTDs, Glider, and VM-ADCP Observations

\begin{tabular}{lllc}
\hline Instrument & Temporal resolution & \multicolumn{1}{c}{ Spatial resolution $(\mathrm{km})$} & Filtering $(\mathrm{km})$ \\
\hline Ship CTD & Survey in 2 days & 5 along leg and 10 between legs & 20 \\
VM-ADCP & Survey in 2 days & 4 along leg and 10 between legs & 20 \\
Shallow glider & GS1 track in 2 days & 0.4 along leg & - \\
Deep glider & GS2 track in 2 days & 1 along leg & - \\
\hline
\end{tabular}

Note. CTD = Conductivity-Temperature-Depth; VM-ADCP = Vessel Mounted-Acoustic Doppler Current Profiler; GS = glider section.

done between 29 and 30 May 2014, with 28 casts made almost at the same positions as Survey 1. CTD stations were spaced $5 \mathrm{~km}$ apart along each leg, while the distance between parallel legs was $10 \mathrm{~km}$. All CTD casts reached 600-m depth. Salinity samples were collected at different depths for salinity calibration. For further details about the CTD data processing, see the cruise report (Ruiz et al., 2015). Direct velocity measurements were collected from a 150-kHz VM-ADCP. This instrument was configured with an 8-m depth bin and a total of 50 bins. Velocity profiles were averaged in 10-min intervals, with an effective spatial resolution of about $4 \mathrm{~km}$ (Table 1).

\subsection{Autonomous Underwater Gliders}

Two Slocum gliders were deployed $10 \mathrm{~km}$ apart in AlborEx and carried out almost parallel north-south transects of $50 \mathrm{~km}$. The gliders performed several transects across the oceanic front (Figure 1c) measuring CTD, fluorescence and oxygen to a depth of $200 \mathrm{~m}$ for the shallow, coastal unit (GS1), and 500-m depth for the deep unit (GS2). The glider profiles have a horizontal, along-track resolution of $0.4 \mathrm{~km}$ for the shallow, coastal glider, and $1 \mathrm{~km}$ for the deep glider (Table 1). Sensors were calibrated by the manufacturers before the deployment, and the compass was calibrated following Merckelbach et al. (2008). Glider data processing (Troupin et al., 2015) includes the thermal lag correction for the unpumped CTD unit, which is standard on Slocum gliders (Garau et al., 2011; Pascual et al., 2010). Data were averaged in the vertical into 1-db bins.

\section{Methods}

\subsection{Statistical Interpolation}

The Statistical Interpolation technique (Daley, 1991) has been used to interpolate ship CTDs and VM-ADCP measurements on to a $2-\mathrm{km}$ grid resolution (see Supporting Information S1). We use a univariate version of a more general scheme described in Gomis et al. (2001). The algorithm requires the definition of three main parameters: (i) The correlation model that in our case is a isotropic Gaussian function with a characteristic scale SCL $=12.5 \mathrm{~km}$ estimated from observations; (ii) the noise-to-signal ratio parameter defined as the ratio between error variance and field variance, $\gamma^{2}=\sigma_{e}^{2} / \sigma^{2}$ allows one to deal explicitly with observational errors. For temperature and salinity, the noise-to-signal ratio was set to $10^{-4}$, considering CTD sensor errors provided by the manufacturer and the variance of the fields. For dynamic height, the maximum error has been estimated in about $0.1 \mathrm{~cm}$ for the interpolated fields at the upper levels. This error is much more smaller than the field variance of the variable, which ensures the good accuracy of the interpolated dynamic height (for further details about the estimation of errors associated with interpolation techniques, see Gomis et al., 2001, Rudnick, 1996); and (iii) the filtering scale parameter that allows us to set the size of structures properly resolved by the sampling design. We use a normal error filter convolution described in Pedder (1993) to filter out features with wavelengths shorter than $20 \mathrm{~km}$ (note that maximum distance between CTD legs is $10 \mathrm{~km}$ ). This last parameter is of importance for avoiding noisy fields generated by second-order derivatives (e.g., vertical velocity). Note that filtering to eliminate scales $<20 \mathrm{~km}$ is applied to all the fields derived from ship CTDs and VM-ADCP; however, glider observations are not interpolated or filtered, we use their spatial high-resolution (0.4-1 km) along glider track. Finally, for the sake of clarity of the interpolated data used in the estimation of the $w_{\mathrm{QG}}$, the methodological process is as follows: First of all, we use the original temperature, salinity, and pressure profiles collected from ship CTD casts to compute density and dynamic height (glider observations are not considered in the QG analysis). Then, observed and derived variables (temperature, salinity, density, and dynamic height) are interpolated onto a 2-km grid using the statistical 
interpolation technique, which includes the filtering of wavelengths shorter than $20 \mathrm{~km}$. Using the interpolated and filtered fields of density, dynamic height, and associated geostrophic velocity, we estimate the $w_{\mathrm{QG}}$ vertical velocities onto the 2-km grid resolution with the QG Omega equation.

\subsection{QG Omega Equation}

The $Q$ vector formulation of the QG omega equation (Hoskins et al., 1978) used to diagnose the vertical velocity associated with the mesoscale features is given by

$$
\nabla_{\mathrm{h}}^{2}\left(N^{2} w\right)+f^{2} \frac{\partial^{2} w}{\partial z^{2}}=2 \nabla_{\mathrm{h}} \cdot \vec{Q}
$$

where

$$
\vec{Q}=\left(f\left(\frac{\partial v_{\mathrm{g}}}{\partial x} \frac{\partial u_{\mathrm{g}}}{\partial z}+\frac{\partial v_{\mathrm{g}}}{\partial y} \frac{\partial v_{\mathrm{g}}}{\partial z}\right),-f\left(\frac{\partial u_{\mathrm{g}}}{\partial x} \frac{\partial u_{\mathrm{g}}}{\partial z}+\frac{\partial u_{\mathrm{g}}}{\partial y} \frac{\partial v_{\mathrm{g}}}{\partial z}\right)\right)
$$

Here $N$ is the Brunt Väisälä frequency, $f$ is the planetary vorticity, $\left(u_{\mathrm{g}}, v_{\mathrm{g}}\right)$ are the geostrophic velocity components, $\nabla_{\mathrm{h}}$ is the horizontal gradient operator, $w$ is the vertical component of the velocity, and $(x, y, z)$ are axes set with $z$ positive upward. We set $w=0$ at the upper $(5 \mathrm{~m})$ and lower $(550 \mathrm{~m})$ boundaries, use Neumann boundary conditions at the lateral boundaries, and solve the Omega equation (1) with an iterative relaxation method (Pinot et al., 1996). To minimize the effect of the imposed boundary conditions, we solve the 3-D Omega equation on a larger grid than the domain covered by ship CTD observations (Figure 1c) but present the solution only within the inner domain.

\subsection{Submesoscale-Resolving Model}

The PSOM (Mahadevan et al., 1996a; 1996b) is configured in a periodic channel that extends $200 \mathrm{~km}$ in the meridional direction, $128 \mathrm{~km}$ in the zonal direction, and $550 \mathrm{~m}$ in the vertical. The model is initialized with a hydrographic section sampled during the AlborEx campaign, specifically, with temperature (T) and salinity (s) from the GS1 glider transect (see initial condition in Supporting Information S1) interpolated on to the model grid. Since the extent of the numerical domain exceeds the glider spatial coverage (about $47 \mathrm{~km}$ cross-front and $167 \mathrm{~m}$ in depth), $2 \mathrm{~km}$ resolution output from the Western Mediterranean Operational Model (WMOP) (Juza et al., 2016) is used to extend the interpolated glider section. The WMOP simulation assimilates observations from Leg 1 of the CTD Survey 1 and ARGO floats nearby the AlborEx region in previous days, as well as altimeter Sea Level Anomaly and satellite Sea Surface Temperature over the entire regional domain. A section of the WMOP output for 27 May 2019 is then interpolated on to the GS1 glider transect and used to extend the glider section laterally and vertically. This extension is performed using gradients of $\mathrm{T}$ and $\mathrm{s}$ from the WMOP section interpolated on to the PSOM model grid. At the meridional edges, vertical profiles are repeated over added $30 \mathrm{~km}$ wide lateral regions, contiguous to the north and south walls, to minimize the influence of these solid boundaries on the evolution of the flow within the domain of interest. Finally, a moving running average is applied laterally (window length is $2.5 \mathrm{~km}$ ) to smooth potential discontinuities. For initialization, the resulting $\mathrm{T}$ and $\mathrm{s}$ cross-front sections are used along the meridional direction and repeated zonally over a $128 \mathrm{~km}$ long periodic channel. The north-south walls and channel bottom are no-flux solid boundaries, while the top is a free-surface boundary. The lateral resolution of the domain is $500 \mathrm{~m}$, while the vertical resolution ranges from $2.3 \mathrm{~m}$ near the surface to $4.2 \mathrm{~m}$ at the bottom. At initialization, PSOM eliminates density inversions and resets any negative potential vorticity (PV) to zero within a few days. A Laplacian subgrid scale closure is used with constant lateral and vertical eddy diffusion coefficients of 1 and $10^{-5} \mathrm{~m}^{2} / \mathrm{s}$, respectively. The zonal velocity is initialized in thermal-wind balance with the density distribution, and the free-surface elevation is initialized so that barotropic and baroclinic pressure gradients cancel each other at the bottom of the domain. Meteorological instruments onboard the $\mathrm{R} / \mathrm{V}$ SOCIB recorded weak winds (less than $10 \mathrm{~m} / \mathrm{s}$, except during the last day of the cruise) with high variability in the wind direction (not shown). Our study does not focus on the effects of wind, which will be discussed in future work. Therefore, no atmospheric forcing is prescribed, and the model flow field evolves in response to mesoscale and submesoscale baroclinic and barotropic instability.

The wavelength $\lambda$ and growth rate $\tau$ of the most unstable mixed-layer baroclinic mode are computed in terms of the balanced Richardson number (Ri) and the Burger number (Bu) following Badin et al. (2011) as

$$
\tau=f \sqrt{\frac{5 / 54}{1+\mathrm{Ri}+\mathrm{Ri} \mathrm{Bu}}}, \quad \text { and } \quad \lambda=\frac{4 \pi}{\sqrt{10}} L_{s} \sqrt{1+\frac{1}{\mathrm{Ri}}+\frac{\mathrm{Bu}}{2}} .
$$


For the modeled front, the Richardson number $\mathrm{Ri}=N^{2} f^{2} / b_{y}^{2}$, where $b_{y}$ is the meridional buoyancy gradient and $N^{2}=b_{z}$ is the vertical buoyancy gradient. Additionally, $\mathrm{Bu}=\left(L_{s} / L_{f}\right)^{2}$, where $L_{s}=b_{y} H / f^{2}$ is the Rossby radius of deformation or the submesoscale length scale for a given mixed-layer depth $H$ and frontal width $L_{f}$. In order to compute Ri and Bu numbers to ultimately estimate $\tau$ and $\lambda$, we use values of $b_{y}=3.8 \times 10^{-7} \mathrm{~s}^{-2}$ and $b_{z}=1.8 \times 10^{-4} \mathrm{~s}^{-2}$, which correspond to volume-averaged values over the frontal region, as in Fox-Kemper et al. (2008), considering only the part initialized with high-resolution glider data.

\subsection{PV}

PV is computed to evaluate whether symmetric instability (SI) is possible. The Ertel PV ( $\Pi$ ) is derived from model output according to $\Pi=1 / \rho_{0}(\vec{\omega}+f \vec{k}) \cdot \vec{\nabla} \rho$, where $\vec{\omega}$ is the relative vorticity vector, $\vec{\nabla}$ the gradient operator, $\rho$ is density, and $\rho_{0}$ is a reference density of $1,027 \mathrm{~kg} / \mathrm{m}^{3}$. When PV is negative (positive), the flow is symmetrically unstable (stable) (Hoskins, 1974).

\subsection{Ecological Model}

A Nutrient-Phytoplankton ecological model is coupled to PSOM. This model consists of two prognostic tracers, phytoplankton $(P)$ and a generic macronutrient $(M)$, which are expressed in units of nitrogen concentration $\left(\mathrm{mmol} / \mathrm{m}^{3}\right)$.

The model is constructed in the same way as conventional Nutrient-Phytoplankton-Zooplankton models (Franks, 2002), using functional forms that add together so that nitrogen is conserved. Here we use functional forms for phytoplankton growth based on Oguz et al. (2014), who implemented a higher-complexity ecological model in the Alboran Sea, namely,

$$
\begin{gathered}
\frac{\partial P}{\partial t}+\vec{u} \cdot \overrightarrow{\nabla P}=G P-\mu_{0} P+k_{\mathrm{h}} \nabla_{\mathrm{h}}^{2}(P)+\partial_{z}\left(k_{z} \partial_{z}(P)\right), \\
\frac{\partial M}{\partial t}+\vec{u} \cdot \overrightarrow{\nabla M}=-G P+\mu_{0} P+k_{\mathrm{h}} \nabla_{\mathrm{h}}^{2}(M)+\partial_{z}\left(k_{z} \partial_{z}(M)\right) .
\end{gathered}
$$

Above, $\vec{u}$ is the three-dimensional velocity vector, $\nabla$ the gradient operator, $\nabla_{\mathrm{h}}^{2}$ the horizontal Laplacian operator, and $\partial_{z}$ the partial derivative with respect to $z$. The first two terms in the right-hand side of (3) and (4) are biological sources minus sinks, while the last two terms are the horizontal and vertical diffusion terms with diffusivities $k_{\mathrm{h}}$ and $k_{\mathrm{v}}$, respectively. Phytoplankton increases due to a growth rate $G$, where

$$
G=\gamma_{0} \frac{M}{\kappa_{0}+M} L
$$

and decreases at a constant rate $\mu_{0}$. The maximum growth rate $\gamma_{0}$ is limited by nutrients, following a conventional Monod curve modulated by $\kappa_{0}$ and by light availability. The light limitation term (L) follows a saturating response as a function of $\alpha_{0}$ according to $\mathrm{L}=\tanh \left(\alpha_{0} \mathrm{I}\right)$, where the radiation at a given location $(I)$ is the result of a time-dependent surface solar radiation $\left(I_{\mathrm{s}}\right)$ attenuated by sea water and phytoplankton self-shading as

$$
I(x, y, z, t)=I_{\mathrm{s}}(t) \exp \left(s_{0} z-a_{0} \int_{z}^{0} P\left(z, y, z^{\prime}, t\right) \mathrm{d} z^{\prime}\right) .
$$

Above, $s_{0}$ and $a_{0}$ are the attenuation coefficients for sea water and phytoplankton self-shading, respectively. The time dependence of $I_{\mathrm{s}}$ follows a piecewise sinusoidal function that is fit to daily time series of Photosynthetically Available Radiation data interpolated from the European Centre for Medium-Range Weather Forecasts (ECMWF) ERA-interim 6-hourly analyses on to the coastal glider time frame (Olita et al. 2017), according to

$$
I_{s}(t)=\left\{\begin{array}{ll}
I_{0}\left(1-\cos \left[(h-4.5) \frac{\pi}{9}\right]\right) / 2 & h \in(4.5,22.5) \\
0 & h \notin(4.5,22.5)
\end{array}\right\},
$$

where $I_{0}$ is the maximum surface radiation and $h$ is the hour of the day. The ecological parameters (Table 2) characterize the ecosystem response to the circulation of the Alboran Sea (Oguz et al., 2014). Finally, numerical results are compared with observations by converting phytoplankton to chlorophyll using the 106:16 Redfield C:N ratio and a C:Chl- $a$ ratio of 10 . The later ratio is consistent with observations made during the same month as AlborEx from the edge of the anticyclonic gyre in the Alboran Sea (See Table IV in Arin et al., 2002). 
Table 2

Ecological Parameters (Oguz et al., 2014)

\begin{tabular}{llc}
\hline Parameter & \multicolumn{1}{c}{ Definition } & Unit \\
\hline$s_{0}$ & Sea water light attenuation & $0.059 \mathrm{~m}^{-1}$ \\
$\mathrm{a}_{0}$ & Light attenuation by $P$ & $0.04 \mathrm{~m}^{2} / \mathrm{mmol}$ \\
$\alpha_{0}$ & Initial slope of $P$ - $I$ curve & $0.03 \mathrm{~m}^{2} / \mathrm{W}$ \\
$\gamma_{0}$ & $P$ Maximum growth rate & $1.3 \mathrm{day}^{-1}$ \\
$I_{0}$ & Daily maximum surface radiation & $313.5 \mathrm{~W} / \mathrm{m}^{2}$ \\
$\kappa_{0}$ & Half-saturation for $P$ nutrient uptake & $0.5 \mathrm{mmol} \mathrm{m}$ \\
$\mu_{0}$ & $P$ specific mortality rate & 0.06 day $^{-1}$ \\
\hline
\end{tabular}

Note. $I_{0}$ is obtained from European Centre for Medium-Range Weather Forecasts ERA-interim 6-hourly data set.

The ecological model is initialized with initial conditions that are steady solutions to equations (3) and (4) with the ocean at rest. While $P$ is initialized with a constant value arbitrarily small to allow for growth, $M$ is initialized using nitrate data through a two-step process. First, given that Atlantic waters are nutrient-rich compared to Mediterranean waters, $M$ is initialized using two nitrate-density polynomial fits different for each water type (see description in Supporting Information S1). Second, the resulting $M$ distribution is then used to time integrate the ecological model without physics until a ecological steady state is reached. In this way, the well-lit euphotic upper layer is nitrate-depleted, that is, nutrients and light are vertically segregated, so that phytoplankton production can only occur if there is nutrient upwelling. While we acknowledge that these ecological initial conditions are idealized in comparison to the observed Chl and nitrate fields, they allow us to isolate the role of frontal dynamics, particularly upwelling/downwelling, on phytoplankton (Viúdez \& Claret, 2009).

\subsection{Vertical Flux of Phytoplankton}

Finally, to assess how much the downward flux of phytoplankton becomes concentrated within regions of submesoscale downwelling, we construct $A_{f}(F)$, the Probability Density Function (PDF) of the flux $F=$ $w$. Chl at a given depth. The PDF, $A_{f}(F)$, normalized to 1 , is also the fraction of the area experiencing the flux $F$ given that the area of grid cells is constant over the numerical model domain. Then, for negative fluxes only, we take the functional inverse of the PDF, that is, $F\left(A_{f}\right)$, and sort it in ascending order of $A_{f}$. This sorting allows to compute the cumulative flux $C\left(A_{f}\right)$ associated with $A_{f}$ fraction of the area as

$$
C\left(A_{f}\right)=\frac{\int_{0}^{A_{f}} F\left(A^{\prime}\right) \mathrm{d} A^{\prime}}{\int_{0}^{1} F\left(A^{\prime}\right) \mathrm{d} A^{\prime}}
$$

$C\left(A_{f}\right)$ is the cumulative downward flux (between 0 and 1) that occurs within the fractional area $A_{f}$.

\section{Results}

\subsection{Mesoscale and Submesoscale Biogeochemical Footprints}

The mesoscale front detected at the surface by sea surface temperature and surface salinity (Figures $1 \mathrm{~b}$ and 1c) results from the confluence of Atlantic waters with salinity values of 36.5-37.5 and the resident Mediterranean waters with a salinity 38-38.5 (Figure 2a). This confluence has been described in terms of surface circulation in Pascual et al. (2017) using the absolute dynamic topography and associated geostrophic currents from altimetry. Although Mediterranean waters are generally nutrient-depleted, high values of Chlorophyll-a (Chl) ranging from 1-1.5 mg/ $\mathrm{m}^{3}$ were commonly observed (Figure 2a) during the cruise. The gliders and the ship's CTD revealed a horizontal density variation of about $0.9 \mathrm{~kg} / \mathrm{m}^{3}$ over a distance of approximately $10 \mathrm{~km}$ (Figure $2 \mathrm{~b}$ ) across the front.

The hydrographic vertical structure of this front is revealed in the glider sections (Figures 3 and 4) and shows outcropping salinity and density isolines between $36.95^{\circ} \mathrm{N}$ and $37^{\circ} \mathrm{N}$ latitude. While the majority of the horizontal density contrast across the front is due to salinity as seen from the T-S diagram (Figure 2a), thermal stratification contributes much of the vertical density gradient (Figures 3 and 4). Fluorometrically derived Chl and oxygen reveal a DCM that is most intense between $\rho_{\theta}=1,027$ and $1,027.5 \mathrm{~kg} / \mathrm{m}^{3}$ at 30 to 

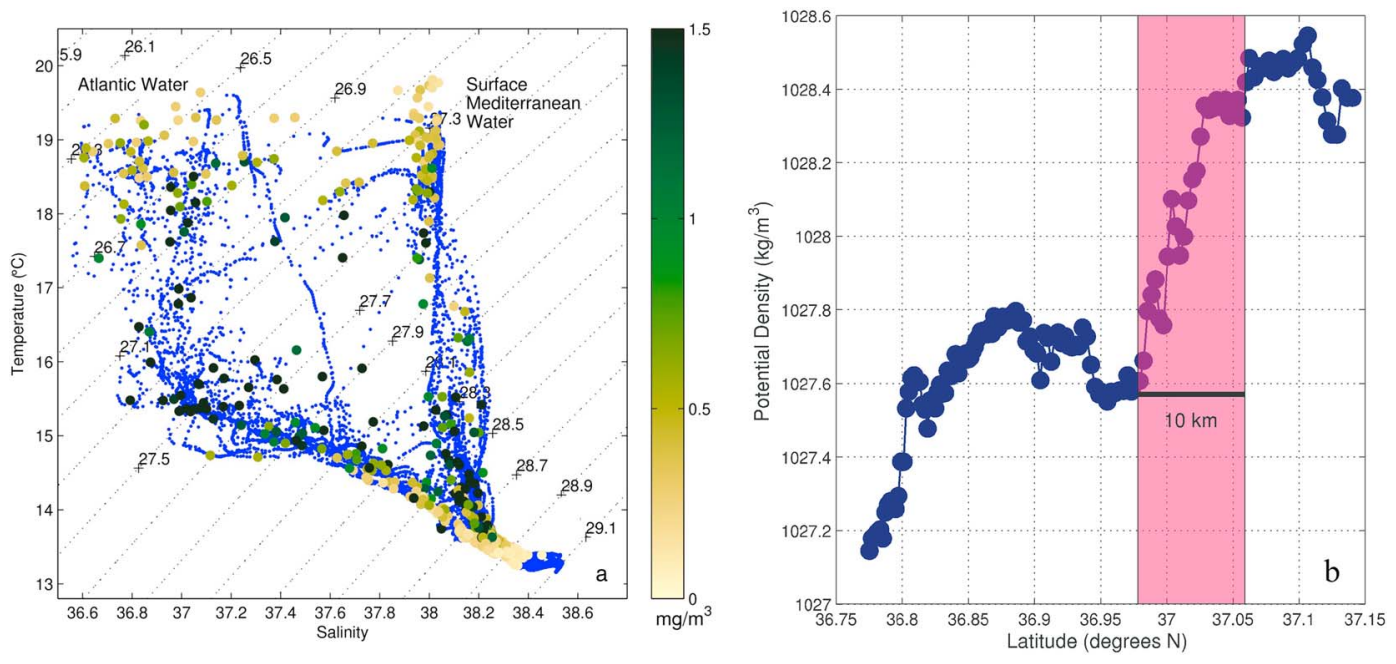

Figure 2. (a) Temperature-salinity diagram showing the two dominant waters (small blue dots) occupying the upper $500 \mathrm{~m}$ of the water column in the eastern Alboran Sea. These temperature-salinity profiles are from stations occupied by the research vessel SOCIB (denoted by squares in Figure 1c) over a period of 1.5 days and show a clear distinction between fresh Atlantic Water and saltier resident Mediterranean water. The color bar corresponds to Chlorophyll-a from waters samples collected at different depths during the cruise. (b) Potential density $\left(\mathrm{kg} / \mathrm{m}^{3}\right)$ at $50 \mathrm{~m}$ depth from shallow glider section GS1.

$40 \mathrm{~m}$ depth on the fresher, Atlantic side of the front but deeper than $50 \mathrm{~m}$ and $\rho_{\theta}=1,028.5$ on the saltier, Mediterranean side. Within the 4 to $5 \mathrm{~km}$ wide frontal zone (latitude $36.95-37.05^{\circ} \mathrm{N}$ ), the DCM is vertically displaced and forms small but sharp filaments of Chl, 1-2 km in horizontal extent at a depth of 80-100 m (Figure 3d). Given the known exponential attenuation of light with depth (Zielinski et al., 2002) and the absence of phytoplankton production for depths exceeding $60 \mathrm{~m}$ in this data set (Olita et al., 2017), our observations (Figure $3 \mathrm{~d}$ ) raise the possibility that the $\mathrm{Chl}$ was subducted by along-isopycnal submesoscale downwelling (Olita et al., 2017) on the dense side of the front.

Apparent Oxygen Utilization (AOU) provides a complementary interpretation of the dynamics affecting the observed Chl patterns. AOU is a time-integrated diagnostic, with positive values indicating that respiration exceeds production since last contact with the atmosphere. The distributions of oxygen and the estimated AOU are consistent with the dynamical view provided by the Chl. The zero AOU contour, which demarcates photosynthetically active waters, is as shallow as $30 \mathrm{~m}$ on the fresher side of the front but is at $60 \mathrm{~m}$ depth on the denser side (Figures $3 \mathrm{e}$ and $4 \mathrm{e}$ ). Within the sharp frontal zone, waters with high oxygen and negative AOU are subducted to depths of $80 \mathrm{~m}$. Narrow tongues of negative AOU intrude downward and are a signature of subduction and export of near-surface waters. The buoyancy frequency (Figures $3 \mathrm{f}$ and $4 \mathrm{f}$ ) reveals shallow density stratification (at $25-30 \mathrm{~m}$ ) on the fresher side and intense stratification extending to $60 \mathrm{~m}$ depth on the dense side but very weak stratification within the near-surface frontal zone.

To diagnose vertical motion, we apply the QG omega equation (1) (Hoskins et al., 1978) to the 3-D interpolated hydrographic CTD data from Survey 2. Our analysis yields maximum upwelling and downwelling rates of $\pm 10 \mathrm{~m} /$ day at $50 \mathrm{~m}$ depth (Figure $5 \mathrm{a}$ ) in an alternating pattern across- and along-front. Such QG mesoscale vertical motion can uplift nutrient-rich isopycnals on the light side of the front, relative to the dense side and shape the large-scale asymmetry in the depth of $\mathrm{Chl}$ and oxygen on one side of the front compared to the other. Note that the pattern of diagnosed downwelling and the position of the front (Figure 3) are not exactly colocated due to the different resolution of glider and ship CTD observations, which are not fully synoptic. This QG analysis performed here for Ro $=\sim 0.3$ is in agreement with the dynamic picture of upward/downward motion upstream/downstream of the flow associated with a mesoscale anticyclonic gyre. The increase/decrease in the sum of the relative and planetary vorticity $(\zeta+f)$ corresponds with downward/upward motions, respectively (Viúdez et al., 1996). But it does not explain the large vertical excursions (up to 90 to $100 \mathrm{~m}$ depth) of Chl and oxygen seen within the sharp frontal zone by the gliders (Figures 3 and 4 ). These vertical excursions are $\approx 10 \mathrm{~m}$ in thickness, $1-5 \mathrm{~km}$ in horizontal extent, and more or less aligned with the sloping isopycnals. 

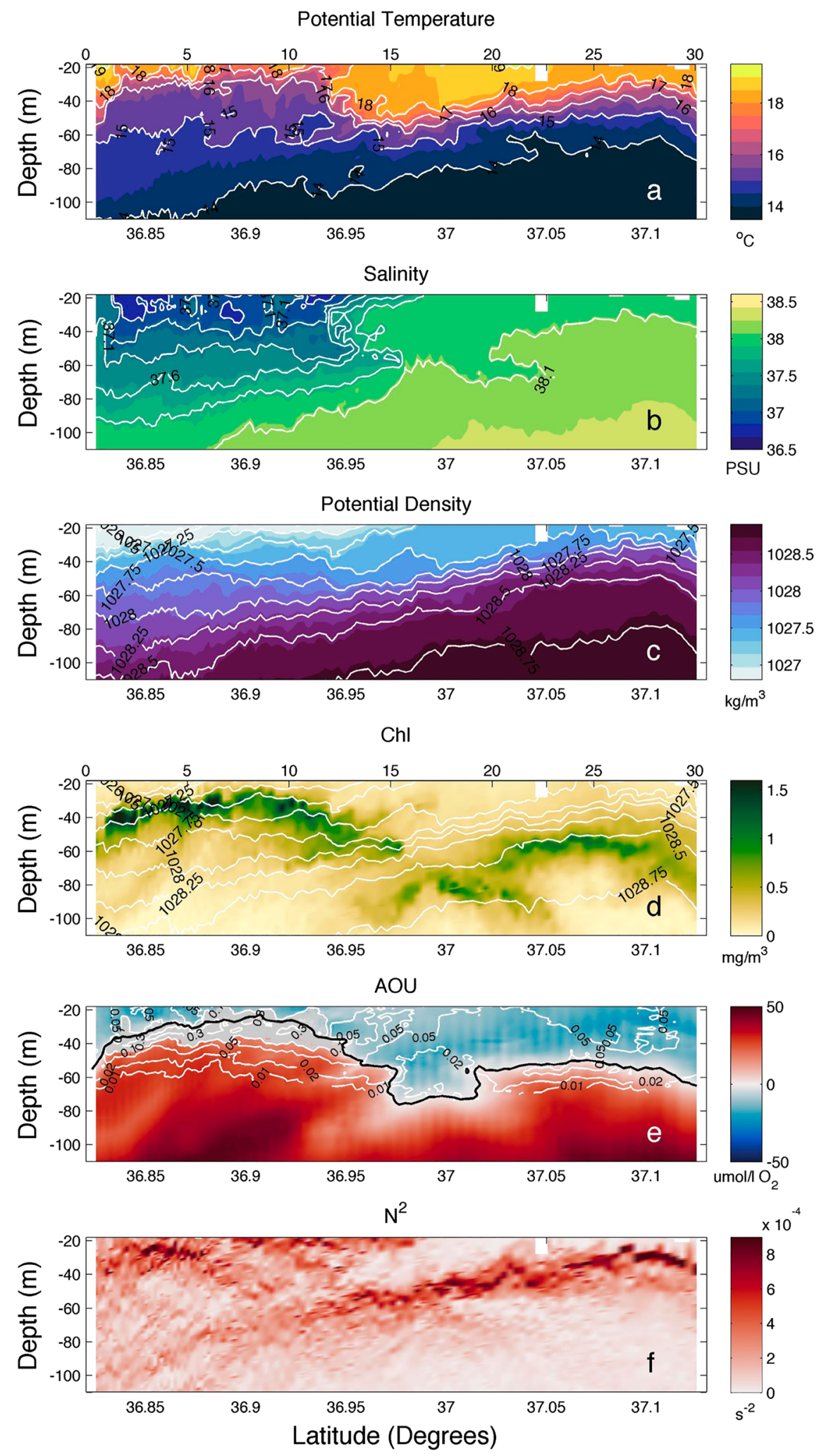

Figure 3. Vertical sections of (a) potential temperature $\left({ }^{\circ} \mathrm{C}\right)$, (b) salinity, (c) potential density $\left(\mathrm{kg} / \mathrm{m}^{3}\right)$, (d) Chl-a $\left(\mathrm{mg} / \mathrm{m}^{3}\right)$, (e) AOU ( $\left.\mu \mathrm{mol} / \mathrm{L}\right)$, and (f) buoyancy frequency $\mathrm{N}^{2}\left(\mathrm{~s}^{-2}\right)$ for glider section 1 (GS1). White isolines on the Chl plot correspond to potential density, black line in AOU figure indicates AOU saturation, and white isolines represent primary production (Olita et al., 2017), with gray highlighting primary production in the range $0.1-0.5 \mathrm{~g} \mathrm{C} \cdot \mathrm{m}^{-3} \cdot \mathrm{day}^{-1}$. Distance (km) along the $x$ axis is indicated on top of (a) and (d). AOU = Apparent Oxygen Utilization. 

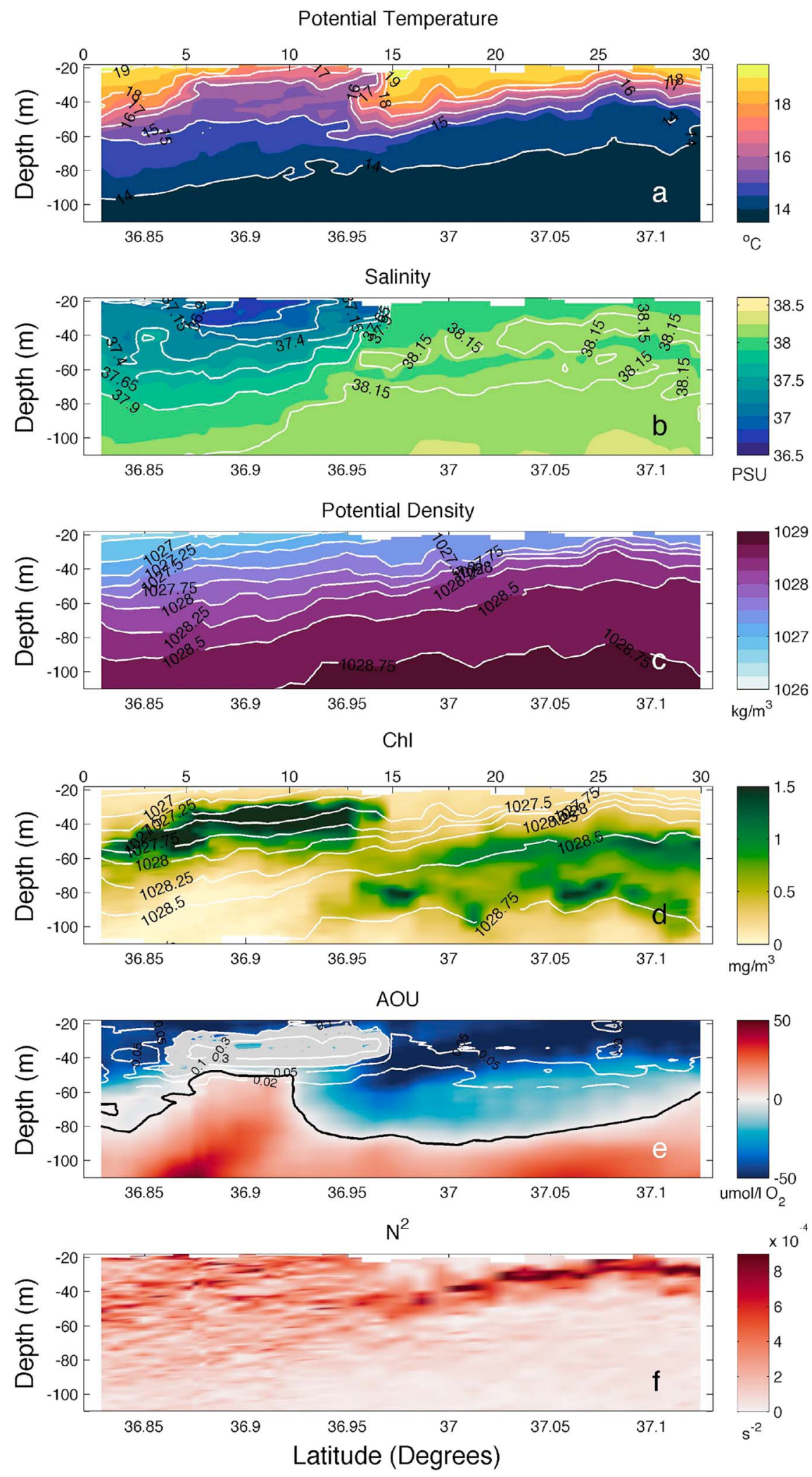

Figure 4. Identical to Figure 3 but for glider section 2 (GS2). 

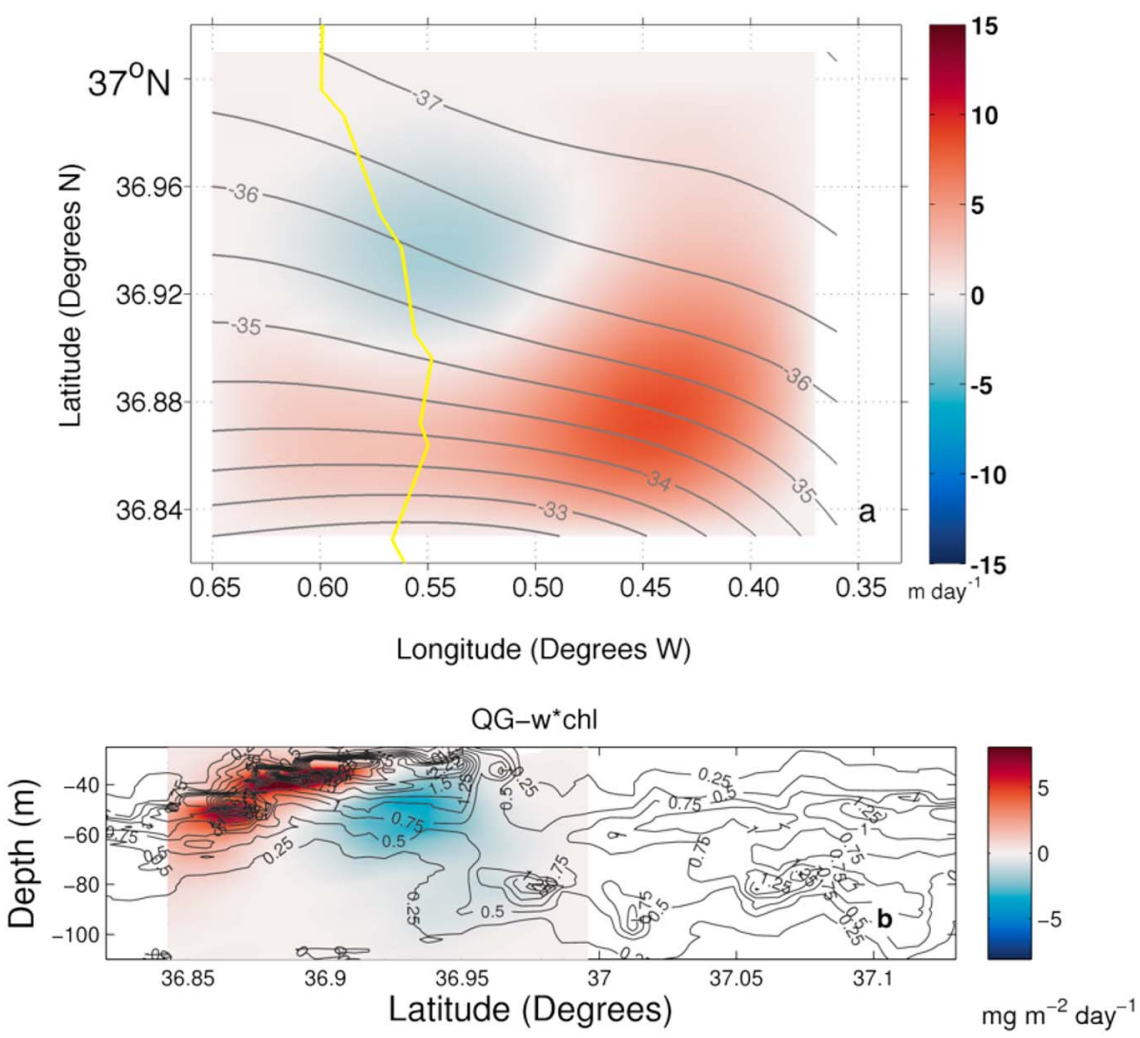

Figure 5. (a) Quasi-geostrophic vertical velocity (m/day) at $50 \mathrm{~m}$ depth from Conductivity-Temperature-Depth Survey 2, which took place between 29 May 2014 12:30 P.M. and 30 May 2014 10:04 P.M. The yellow line indicates the track of GS2 (deep glider; date is indicated in Figure 1c). Gray contours correspond to dynamic height $(\mathrm{cm})$ interpolated from the Conductivity-Temperature-Depths. (b) Mesoscale vertical transport of chlorophyll-a estimated as the product of the mesoscale vertical velocity $w_{\mathrm{QG}}$ and chlorophyll-a, expressed in milligram per square meter per day, for GS2, where $w_{\mathrm{QG}}$ is estimated from the QG omega equation. Red/blue colors denote upward/downward fluxes of phytoplankton (chlorophyll) in the frontal region due to the secondary circulation. Gray contours denote Chlorophyll $\left(\mathrm{mg} / \mathrm{m}^{3}\right)$.

Frontogenesis theory (Hoskins, 1982) suggests that the intensification of a front due to horizontal strain and convergence leads to large relative vorticity, O(1) Rossby number, a deviation from geostrophic balance, and consequently an ageostrophic motion on both sides of the front (upwelling on the less dense side of the front and downwelling on the dense side). The mesoscale frontogenetic term (not shown) has been diagnosed from the 3-D interpolated ship's CTD observations and shows areas of strong intensification/relaxation (positive/negative values), revealing that buoyancy gradients evolve not only perpendicular to the front but also along the front. Therefore, our observations suggest that mesoscale frontogenesis intensifies the front and its relative vertical vorticity causes a local increase in the Rossby number. This invokes an ageostrophic response at the front and can explain the large vertical excursions in Chl (Figures 3d and 4d) and oxygen that are narrow in horizontal extent and observed in high-resolution glider measurements.

To further illustrate this point, the vertical transport of $\mathrm{Chl}$ is estimated using the $\mathrm{QG}$ vertical velocity, $w_{\mathrm{QG}}$ as $w_{\mathrm{QG}} \cdot$ Chl at Glider Section GS2 (Figure 5b). Intense vertical transport is confined in the upper $60 \mathrm{~m}$ with upward (downward) flux occurring on the less (more) dense side of the front. Downward flux of chlorophyll occurs where the vertical displacement of $\mathrm{Chl}$ is the largest at the rate of $-1 \mathrm{mg} \mathrm{Chl} \cdot \mathrm{m}^{-2}$. day ${ }^{-1}$ below $60 \mathrm{~m}$. Thus, $w_{\mathrm{QG}}$ would take about 30 days to advect $1 \mathrm{mg} \mathrm{Chl} / \mathrm{m}^{3}$ from 60 to $90 \mathrm{~m}$ depth, in which time it would decay. Although this is a gross approximation of a mesoscale-driven subduction time scale, it suggests that $\mathrm{Chl}$ must be advected more quickly by a more intense submesoscale vertical velocity, since typical phytoplankton mortality time scales are less than 30 days.

\subsection{Model Simulations of Mesoscale and Submesoscale Ocean Frontal Processes}

Given the strongly ageostrophic nature of the frontal dynamics, we use the submesoscale-resolving PSOM to examine the vertical flux of tracers and phytoplankton resulting from baroclinically unstable frontal processes in the absence of atmospheric forcing. Numerical solutions show that the initially balanced front 

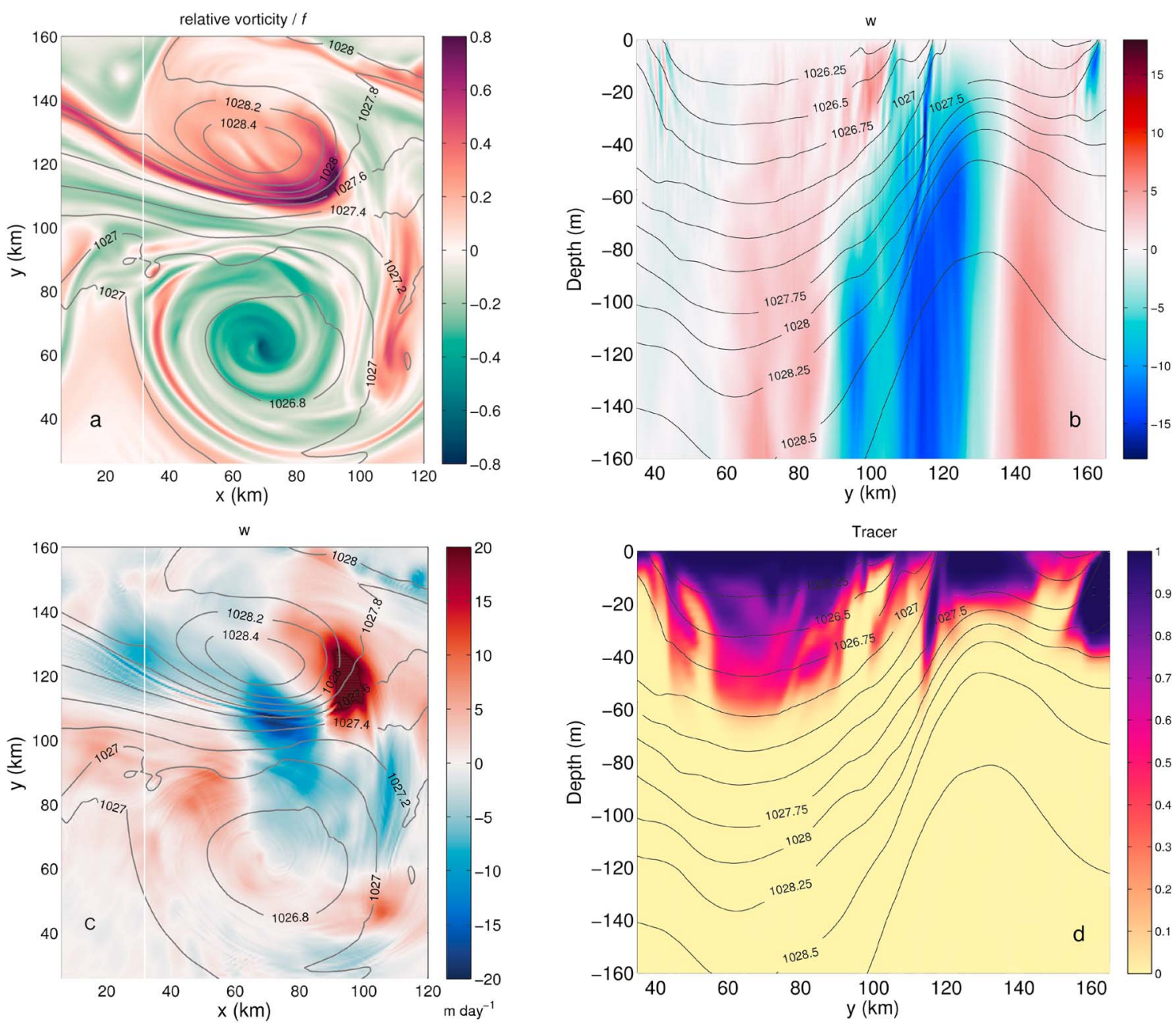

Figure 6. (a) A horizontal section of relative vertical vorticity normalized by $f$ at $51 \mathrm{~m}$ depth from a simulation performed with the Process Study Ocean Model (Day 33). Gray contours correspond to density $\left(\mathrm{kg} / \mathrm{m}^{3}\right)$; white line shows the location of the sections in (b) and (d). (b) Modeled vertical velocity (m/day), red/blue denote upward/downward motion. Gray contours represent density $\left(\mathrm{kg} / \mathrm{m}^{3}\right)$; (c) horizontal section of vertical velocity (color), units are meters per day, and potential density $\left(\mathrm{kg} / \mathrm{m}^{3}\right)$ black (isolines) from the Process Ocean Study model at $51 \mathrm{~m}$ depth. White line corresponds to the location of the vertical section showed in (b). (d) Vertical mixed-layer tracer associated with section (b) with density contours $\left(\mathrm{kg} / \mathrm{m}^{3}\right)$.

becomes baroclinically unstable after about 13 days, developing meanders at the surface with wavelength of about $14 \mathrm{~km}$ (not shown). This wavelength is close to that of the most unstable ageostrophic instability mode estimated theoretically (Badin et al., 2011; see section 3). Considering a front width of about $10 \mathrm{~km}$ for AlborEx (Figure 2b) and a typical mixed-layer depth for the transition period from spring to summer in this region of $50 \mathrm{~m}$ (Houpert et al., 2015), the wavelength and growth time scale of the fastest mixed-layer instability mode are about $11 \mathrm{~km}$ and 1.17 days, respectively. The meandering of the front causes the local lateral buoyancy gradients to evolve. In regions undergoing frontogenesis, the confluence of water masses forming the front strengthens so that the relative vorticity, $\zeta$, becomes $\mathrm{O}(f)$ (Figure 6a). In these regions, the circulation departs from geostrophy, being dynamically submesoscale, and generating $w$ as large as $20 \mathrm{~m} /$ day (Figure 6b). This is twice $w_{\mathrm{QG}}$ estimated from observational data, which assumes $\zeta \ll f$.

In order to quantify the vertical extent of the frontal transport, we introduce a passive tracer, initially only within the mixed layer, the depth of which is defined by a density difference of $0.01 \mathrm{~kg} / \mathrm{m}^{3}$ from the surface. The tracer can be viewed as an abiotic representation of oxygen saturation, which is 1 within an unstratified, well-mixed surface mixed layer in equilibrium with the atmosphere. As the front becomes unstable, the distribution of the mixed-layer tracer responds to mesoscale modulations in the mixed-layer depth (Figure 6d) while forming submesoscale intrusions (less than $10 \mathrm{~km}$ in width) that penetrate to a depth of $70 \mathrm{~m}$. In the sharp frontal region (lying between $x=100$ and $120 \mathrm{~km}$ in Figure $6 \mathrm{~d}$ ), the most intense tracer filament corre- 

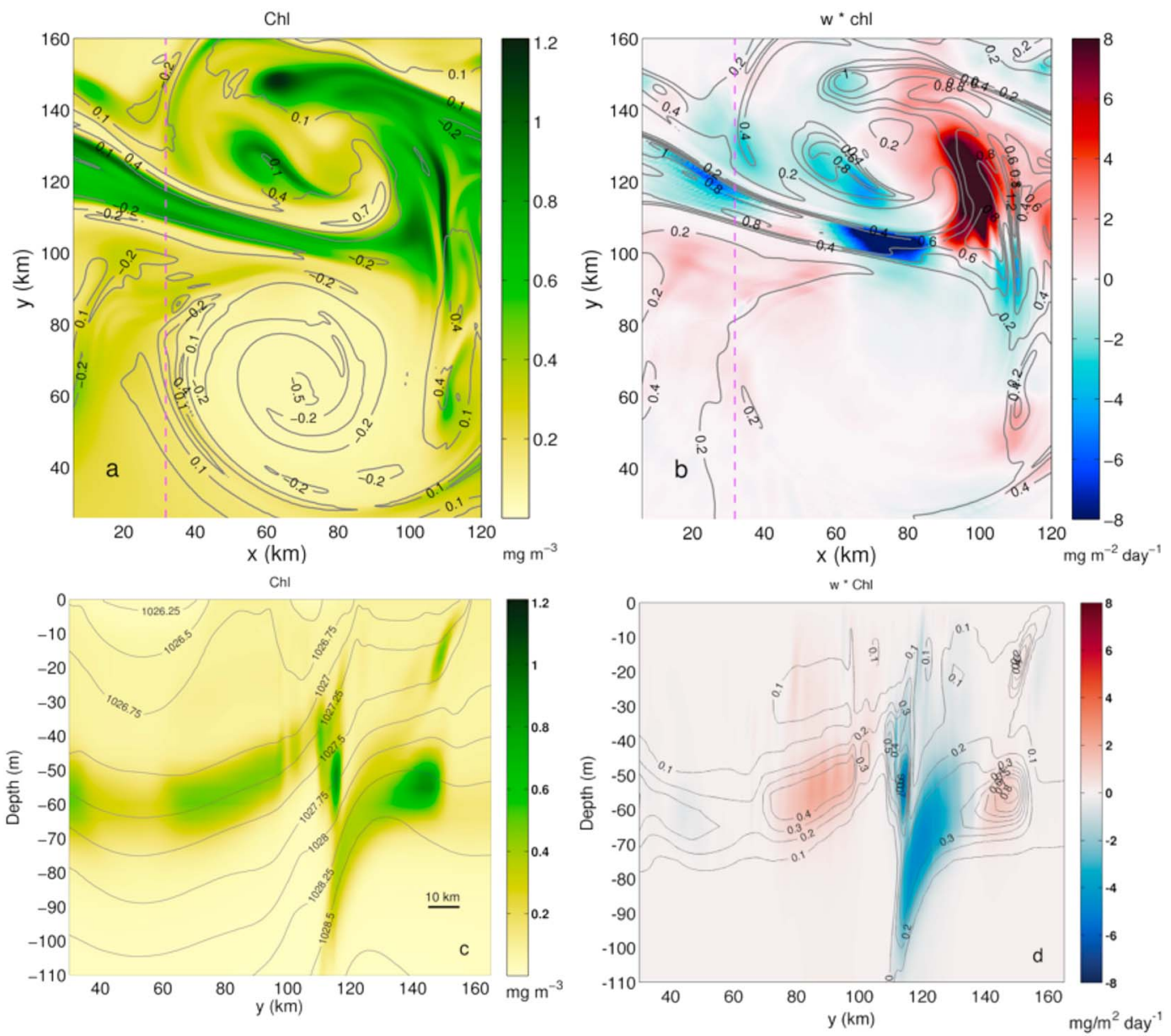

Figure 7. (a) A horizontal section at $51 \mathrm{~m}$ depth of modeled Chlorophyll-a $\left(\mathrm{mg} / \mathrm{m}^{3}\right)$, a proxy for phytoplankton, with contours showing the normalized relative vorticity $\zeta / f$. (b) Horizontal section at $51 \mathrm{~m}$ depth of modeled vertical tracer flux wChl that is obtained as the product of the vertical velocity and chlorophyll-a. Red/blue indicate upwelling/downwelling. Contours correspond to Chlorophyll-a. (c) Vertical section of Chlorophyll-a (mg/m $\left.\mathrm{m}^{3}\right)$ and contours of density $\left(\mathrm{kg} / \mathrm{m}^{3}\right)$ at the location denoted with a magenta line in (a). (d) Vertical tracer flux wChl at the section denoted by a magenta line in (b) is consistent with the pattern seen in (c). Contours in (d) correspond to Chlorophyll-a.

lates with strong downwelling and is being actively subducted at the time visualized in the figure, while the filament next to it could also be the result from vertical shear in the horizontal velocities (Shcherbina et al., 2010). Additionally, tracer seen at depth in upwelling regions can only be explained by horizontal advection, which transports tracers away from downwelling regions within a few days (Viúdez \& Claret, 2009). The numerical model shows that the lateral buoyancy gradients spontaneously trigger baroclinic instability in the mixed-layer and submesoscale dynamics subducts mixed-layer waters in the form of sharp filaments.

\subsection{Impacts of Submesoscale Vertical Velocity on Phytoplankton Distribution}

To quantify the impact of the vertical velocity on chlorophyll, a conventional Nutrient-Phytoplankton model described above is coupled to PSOM. This simple ecological model is initialized with a spatially homogeneous seed of phytoplankton in order to examine its response to frontal dynamics. Once the front becomes baroclinically unstable, the highest values of relative vorticity $\zeta$ and $\mathrm{Chl}$ (Figures 6a and 7a) occur in submesoscale filaments in the frontal zone, where the lateral density/buoyancy gradients are large (see time evolution of chlorophyll and tracer in Supporting Information S1). The secondary circulation impacts the phytoplankton distribution in the frontal zone, with clear evidence for upwelling and more intense downwelling through submesoscale filaments of 1 to $10 \mathrm{~km}$ horizontal extent (Figure 7c). These filaments induce 


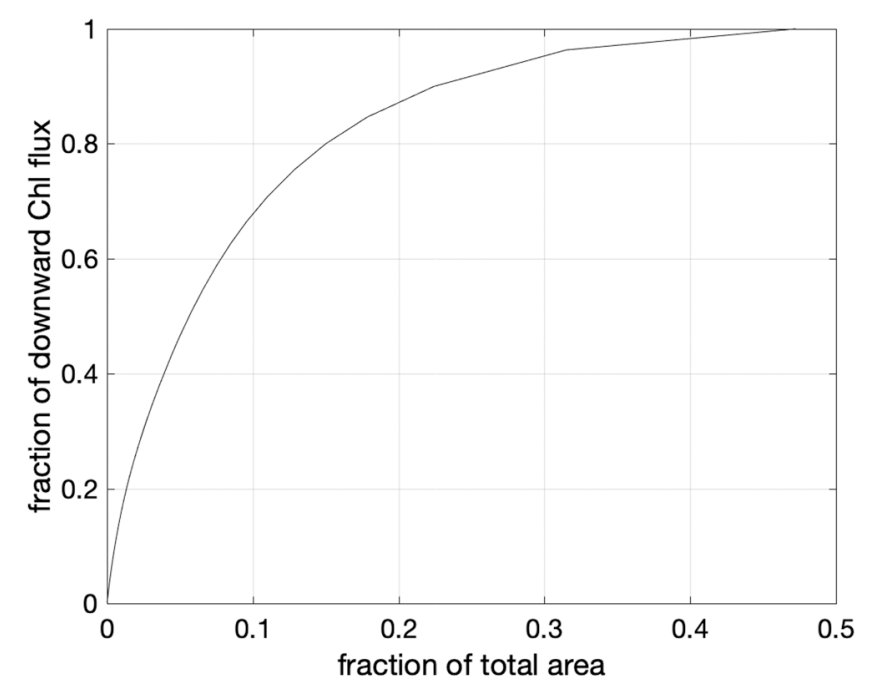

Figure 8. Percent of integrated downward flux of phytoplankton (black line) as a function of fraction of area at $50 \mathrm{~m}$ depth (see equation (7)). an active downward flux of phytoplankton, which can be quantified as $w \cdot$ Chl (Figures $7 \mathrm{~b}$ and $7 \mathrm{~d}$ ). This downward flux reaches about $-4 \mathrm{mg} \cdot \mathrm{m}^{-2} \cdot$ day $^{-1}$ below $60 \mathrm{~m}$ depth, which is four times larger than the estimate of downwelling from observations using the QG omega equation. Since the highest values of Chl concentration occur within filaments characterized by strong downward velocity, most of the vertical export is mediated by those filaments. By calculating the PDF of $w \cdot C h l$ from the model and applying (7), we find that $80 \%$ of the total downward flux of phytoplankton at $50 \mathrm{~m}$ depth occurs within $15 \%$ of the total area of the model domain (Figure 8). This emphasizes the contribution of submesoscale filaments to the net vertical exchange of biogeochemical material across the main pycnocline. Finally, the high downwelling velocity resolved within the filaments allows subducted chlorophyll $\left(\sim 1 \mathrm{mg} / \mathrm{m}^{3}\right)$ to reach a depth of $90 \mathrm{~m}$ (Figure 3) in about 1 week, a time scale on which phytoplankton can stay alive if we assume an $e$-folding decay rate of about 16 days for a phytoplankton mortality rate of 0.06 per day (Oguz et al., 2014). Instead, mesoscale-driven vertical advection would require 30 days to transport phytoplankton to the same depth, during which time the chlorophyll would decay.

\section{Acknowledgments}

The AlborEx experiment was conducted in the framework of PERSEUS EU-funded project (Grant 287600) and was led by the Spanish National Research Council (CSIC) and involved other national and international partners: Balearic Islands Coastal Observing and Forecasting System (SOCIB, Spain); Consiglio Nazionale delle Ricerche (CNR, Italy); Istituto Nazionale di Oceanografia e di Geofisica Sperimentale (OGS, Italy); and Woods Hole Oceanographic Institution (WHOI, ONR Grant N00014-16-1-3130). Glider operations were partially funded by JERICO FP7 project. Part of this work has been carried out as part of the Copernicus Marine Environment Monitoring Service (CMEMS) MedSUB project. CMEMS is implemented by Mercator Ocean in the framework of a delegation agreement with the European Union. S. R. and A. P. acknowledge support from WHOI Subcontract A101339. Data available from authors: Ship CTDs, glider and VM-ADCP data files are available in the SOCIB data catalog (https://doi. org/10.25704/z5y2-qpye); model data are available at IMEDEA data catalog https://ide.imedea.uib-csic.es/thredds/ catalog/data/projects/alborex/catalog. html. We thank all the crew and participants on board R/V SOCIB for their collaboration and Marc Torner and the SOCIB glider Facility for their efficient cooperation. We also thank B. Mourre for numerical data from the Western Mediterranean Operational Model to initialize the Process Study Ocean Model. Figures were created using the cmocean colormaps package (Thyng et al., 2016).
An alternative mechanism that explains vertical excursions of tracers at submesoscales is SI (Brannigan, 2016). The potential role of SI is evaluated using model output, since the lateral spacing of CTD stations is too coarse to resolve SI. A lateral spacing less than $4 \mathrm{~km}$ was found to be necessary to distinctively capture negative PV in a strong front (D'Asaro et al., 2011). The high-resolution glider GS1 hydrographic data are not suitable to compute two-dimensional PV either, because the geostrophic relative vertical vorticity is $O(f)$, and the assumption of geostrophy breaks down. Modeling results show that the advection of Chl filaments to $100 \mathrm{~m}$ depth (Figure 7) correlates with positive PV. The few regions of negative PV that exist in the model do not extend below $40 \mathrm{~m}$ depth. Therefore, we infer that in the model, subduction of Chl down to $100 \mathrm{~m}$ occurs in response to baroclinic instability and not SI.

\section{Concluding Remarks}

Observations made from a ship and gliders reveal a strong front (of more than 1 psu salinity change in $10 \mathrm{~km}$ ) on the eastern flank of an unusual eastern gyre in the Alboran Sea. Bioptical measurements from gliders traversing the front show a distinct DCM at about $35 \mathrm{~m}$ on the Atlantic side and $55 \mathrm{~m}$ on the Mediterranean side. At the front, Chl is subducted 40-60 m below the DCM in narrow features, approximately $10 \mathrm{~m}$ in vertical extent and 1-10 km in horizontal extent across the front. The mesoscale vertical velocity estimated from the ship CTD measurements by the QG omega equation is approximately $\pm 10 \mathrm{~m} / \mathrm{day}$ and is coherent on scales of about $20 \mathrm{~km}$. While this mesoscale upwelling/downwelling shapes the nitracline and DCM, it does not account for the narrow vertical excursions in Chl seen in the glider data. Numerical simulations at 0.5 $\mathrm{km}$ horizontal resolution suggest that baroclinic instability of this sharp front produces frontogenesis, intensifying the density gradients and inducing an ageostrophic response leading to vertical velocities of about $20 \mathrm{~m}$ /day (twice the maximum velocity estimated by the QG omega equation). Advection along-isopycnal surfaces in the numerical model generates vertical excursions in a modeled tracer and phytoplankton that resemble the observations in vertical and horizontal extents. Furthermore, the model shows that most (about $80 \%$ ) of the vertical flux of phytoplankton occurs within just $15 \%$ of the model domain. Our study shows that though there is both mesoscale and submesoscale vertical motion at fronts, it is the along-isopycnal, submesoscale, frontal downwelling that accounts for the majority of the vertical flux of nonsinking phytoplankton carbon and oxygen.

\section{References}

Allen, J. T., Smeed, D. A., Tintoré, J., \& Ruiz, S. (2001). Mesoscale subduction at the almeria-oran front: Part 1: Ageostrophic flow. Journal of Marine Systems, 30(3 - 4), 263-285.

Arin, L., Morán, X. A. G., \& Estrada, M. (2002). Phytoplankton size distribution and growth rates in the Alboran Sea (SW Mediterranean): Short term variability related to mesoscale hydrodynamics. Journal of Plankton Research, 24(10), 1019. 
Ascani, F., Richards, K. J., Firing, E., Grant, S., Johnson, K. S., Jia, Y., et al. (2013). Physical and biological controls of nitrate concentrations in the upper subtropical north Pacific ocean. Deep Sea Research Part II: Topical Studies in Oceanography, 93, 119-134. http://www. sciencedirect.com/science/article/pii/S0967064513000544

Badin, G., Tandon, A., \& Mahadevan, A. (2011). Lateral mixing in the pycnocline by baroclinic mixed layer eddies. Journal of Physical Oceanography, 41(11), 2080-2101. https://doi.org/10.1175/JPO-D-11-05.1

Barkan, R., Molemaker, MJeroen, Srinivasan, K., McWilliams, J. C., \& D'Asaro, E. A. (2019). The role of horizontal divergence in submesoscale frontogenesis. Journal of Physical Oceanography, 49, 1593-1618.

Brannigan, L. (2016). Intense submesoscale upwelling in anticyclonic eddies. Geophysical Research Letters, 43, 3360-3369. https://doi.org/ 10.1002/2016GL067926

Capet, X., McWilliams, J. C., Molemaker, M. J., \& Shchepetkin, A. F. (2008). Mesoscale to submesoscale transition in the california current system. Part II: Frontal processes. Journal of Physical Oceanography, 38(1), 44-64.

Claustre, H., Kerhervé, P., Marty, J. C., Prieur, L., Videau, C., \& Hecp, J.-H. (1994). Phytoplankton dynamics associated with a geostrophic front: Ecological and biogeochemical implications. Journal of Marine Research, 52, 711-742.

D'Asaro, E. A., Lee, C., Rainville, L., Harcourt, R., \& Thomas, L. (2011). Enhanced turbulence and energy dissipation at ocean fronts. Science, 332, 318-322.

Daley, R. (1991). Atmospheric data analysis (pp. 457). Cambridge.

Estrada, M., Marrasé, C., Latasa, M., Berdalet, E., Delgado, M., \& Riera, T. (1993). Variability of deep chlorophyll maximum characteristics in the northwestern Mediterranean. Marine Ecology Progress Series, 92, 289-300.

Fox-Kemper, B., Ferrari, R., \& Hallberg, R. (2008). Parameterization of mixed layer eddies. Part I: Theory and diagnosis. Journal of Physical Oceanography, 38(6), 1145-1165.

Franks, PeterJ. S. (2002). NPZ models of plankton dynamics: Their construction, coupling to physics, and application. Journal of Oceanography, 58(2), 379-387. https://doi.org/10.1023/A:1015874028196

Garau, B., Ruiz, S., Zhang, W. G., Pascual, A., Heslop, E., Kerfoot, J., \& Tintoré, J. (2011). Thermal lag correction on Slocum CTD glider data. Journal of Atmospheric and Oceanic Technology, 28(9), 1065-1071. https://doi.org/10.1175/JTECH-D-10-05030.1

Gascard, J. C., \& Richez, C. (1985). Water masses and circulation in the Western Alboran sea and in the Straits of Gibraltar. Progress in Oceanography, 15(3), 157-216. http://www.sciencedirect.com/science/article/pii/007966118590031X

Gasser, M., Pelegrí, J. L., Emelianov, M., Bruno, M., Gràcia, E., Pastor, M., et al. (2017). Tracking the Mediterranean outflow in the Gulf of Cadiz. Progress in Oceanography, 157, 47-71. https://doi.org/10.1016/j.pocean.2017.05.015.

Gomis, D., Ruiz, S., \& Pedder, M. A (2001). Diagnostic analysis of the 3D ageostrophic circulation from a multivariate spatial interpolation of CTD and ADCP data. Deep Sea Research Part I: Oceanographic Research Papers, 48(1), 269-295.

Hoskins, B. J. (1974). The role of potential vorticity in symmetric stability and instability. Quarterly Journal of the Royal Meteorological Society, 100(425), 480-482.

Hoskins, B. J. (1982). The mathematical theory of frontogenesis. Annual Review of Fluid Mechanics, 14(1), 131-151.

Hoskins, B. J., Draghici, I., \& Davies, H. C. (1978). A new look at the $\omega$-equation. Quarterly Journal of the Royal Meteorological Society, 104(439), 31-38.

Houpert, L., Testor, P., de Madron, X. Durrieu, Somot, S., D'Ortenzio, F., Estournel, C., \& Lavigne, H. (2015). Seasonal cycle of the mixed layer, the seasonal thermocline and the upper-ocean heat storage rate in the Mediterranean sea derived from observations. Progress in Oceanography, 132, 333-352. http://www.sciencedirect.com/science/article/pii/S0079661114001797

Juza, M., Mourre, B., Renault, L., Gómara, S., Sebastián, K., Lora, S., et al. (2016). SOCIB operational ocean forecasting system and multi-platform validation in the Western Mediterranean Sea. Journal of Operational Oceanography, 9(sup1), s155-s166.

Klein, P., \& Lapeyre, G. (2009). The oceanic vertical pump induced by mesoscale and submesoscale turbulence. Annual Review of Marine Science, 1(1), 351-375.

Lapeyre, G., \& Klein, P. (2006). Dynamics of the upper oceanic layers in terms of surface quasigeostrophy theory. Journal of Physical Oceanography, 36(2), 165-176.

Lavigne, H., D'Ortenzio, F., Ribera D'Alcalà, M., Claustre, H., Sauzède, R., \& Gacic, M. (2015). On the vertical distribution of the chlorophyll a concentration in the Mediterranean Sea: A basin-scale and seasonal approach. Biogeosciences, 12(16), 5021-5039. 10.5194/ bg-12-5021-2015

Lévy, M. (2003). Mesoscale variability of phytoplankton and of new production: Impact of the large-scale nutrient distribution. Journal of Geophysical Research, 108(C11), 3358. https://doi.org/10.1029/2002JC001577

Lévy, M., Klein, P., \& Treguier, A.-M. (2001). Impact of sub-mesoscale physics on production and subduction of phytoplankton in an oligotrophic regime. Journal of Marine Research, 59, 535-565.

Mahadevan, A., \& Archer, D. (2000). Modeling the impact of fronts and mesoscale circulation on the nutrient supply and biogeochemistry of the upper ocean. Journal of Geophysical Research, 105(C1), 1209-1225.

Mahadevan, A., Oliger, J., \& Street, R. (1996a). A nonhydrostatic mesoscale ocean model. Part I: Well-posedness and scaling. Journal of Physical Oceanography, 26(9), 1868-1880.

Mahadevan, A., Oliger, J., \& Street, R. (1996b). A nonhydrostatic mesoscale ocean model. Part II: Numerical implementation. Journal of Physical Oceanography, 26(9), 1881-1900.

Mahadevan, A., \& Tandon, A. (2006). An analysis of mechanisms for submesoscale vertical motion at ocean fronts. Ocean Modelling, 14(3-4), 241-256.

McWilliams, J. C. (2016). Submesoscale currents in the ocean. Proceedings of the Royal Society of London A: Mathematical, Physical and Engineering Sciences, 472, 2189.

McWilliams, J. C., Gula, J., \& Molemaker, MJeroen (2019). The gulf stream north wall: Ageostrophic circulation and frontogenesis. Journal of Physical Oceanography, 49(4), 893-916.

Merckelbach, L. M., Briggs, R. D., Smeed, D. A., \& Griffiths, G. (2008). Current measurements from autonomous underwater gliders. In 2008 ieee/oes 9th working conference on current measurement technology, pp. 61-67.

Morán, XoséA. G., Taupier-Letage, I., Vázquez-Domínguez, E., Ruiz, S., Arin, L., Raimbault, P., \& Estrada, M. (2001). Physical-biological coupling in the Algerian Basin (SW Mediterranean): Influence of mesoscale instabilities on the biomass and production of phytoplankton and bacterioplankton. Deep Sea Research Part I: Oceanographic Research Papers, 48(2), 405-437.

Nardelli, B. B. (2013). Vortex waves and vertical motion in a mesoscale cyclonic eddy. Journal of Geophysical Research: Oceans, 118, 5609-5624. https://doi.org/10.1002/jgrc.20345

Oguz, T., Macias, D., Garcia-Lafuente, J., Pascual, A., \& Tintoré, J. (2014). Fueling plankton production by a meandering frontal jet: A case study for the Alboran Sea (Western Mediterranean). PLOS ONE, 9(11), 1-14. 
Olita, A., Capet, A., Mahadevan, A., Claret, M., Ruiz, S., Tintoré, J., et al. (2017). Frontal dynamics boost primary production in the summer stratified Mediterranean Sea. Ocean Dynamics, 67, 767-782.

Omand, M. M., D'Asaro, E. A., Lee, C. M., Perry, M. J., Briggs, N., Cetinić, I., \& Mahadevan, A. (2015). Eddy-driven subduction exports particulate organic carbon from the spring bloom. Science, 348, 222-225.

Pascual, A., Ruiz, S., Nardelli, B. B., Guinehut, S., Iudicone, D., \& Tintoré, J. (2015). Net primary production in the gulf stream sustained by quasi-geostrophic vertical exchanges. Geophysical Research Letters, 42, 441-449. https://doi.org/10.1002/2014GL062569

Pascual, A., Ruiz, S., Olita, A., Troupin, C., Claret, M., Casas, B., et al. (2017). A multiplatform experiment to unravel meso- and submesoscale processes in an intense front (AlborEx). Frontiers in Marine Science, 4, 39.

Pascual, A., Ruiz, S., \& Tintore, J. (2010). Combining new and conventional sensors to study the Balearic Current. Sea Technology, 51-7, 32-36. https://doi.org/10.1126/science. 1260062

Pedder, M. A. (1993). Interpolation and filtering of spatial observations using successive corrections and Gaussian filters. Monthly Weather Review, 121(10), 2889-2902.

Pinot, J.-M., Tintoré, J., \& Wang, D.-P. (1996). A study of the omega equation for diagnosing vertical motions at ocean fronts. Journal of Marine Research, 54(2), 239-259.

Ramachandran, S., Tandon, A., \& Mahadevan, A. (2014). Enhancement in vertical fluxes at a front by mesoscale-submesoscale coupling Journal of Geophysical Research: Oceans, 119, 8495-8511. https://doi.org/10.1002/2014JC010211

Renault, L., Oguz, T., Pascual, A., Vizoso, G., \& Tintore, J. (2012). Surface circulation in the Alboran Sea (Western Mediterranean) inferred from remotely sensed data. Journal of Geophysical Research, 117, C08009. https://doi.org/10.1029/2011JC007659

Rodríguez, J., Tintoré, J., Allen, J. T., Blanco, J., Gomis, D., Reul, A., et al. (2001). Mesoscale vertical motion and the size structure phytoplankton in the ocean. Nature, 410, 360-363.

Rudnick, D. L. (1996). Intensive surveys of the Azores front. Part II: Inferring the geostrophic and vertical velocity fields, Journal of Geophysical Research, 101(C7), 16,291-16,303.

Ruiz, S., Pascual, A., Casas, B., Poulain, P.-M., Olita, A., Troupin, C., et al. (2015). Report on operation and data analysis from multi-platform synoptic intensive experiment (AlborEx) (Technical Report).

Sasaki, H., Klein, P., \& Qiu, B. (2014). Impact of oceanic-scale interactions on the seasonal modulation of ocean dynamics by the atmosphere. Nature Communications, 5, 5636.

Shcherbina, A. Y., Gregg, M. C., Alford, M. H., \& Harcourt, R. R. (2010). Three-dimensional structure and temporal evolution of submesoscale thermohaline intrusions in the North Pacific subtropical frontal zone. Journal of Physical Oceanography, 40(8), 1669-1689.

Stukel, M. R., Aluwihare, L. I., Barbeau, K. A., Chekalyuk, A. M., Goericke, R., Miller, A. J., et al. (2017). Mesoscale ocean fronts enhance carbon export due to gravitational sinking and subduction. Proceedings of the National Academy of Sciences, 114(6), 1252-1257.

Thomas, L., Tandon, A., \& Mahadevan, A. (2008). Submesoscale ocean processes and dynamics. In M. Hecht, \& H. Hasume (Eds.), Ocean modeling in an eddying regime (Vol. 177, pp. 17-38): Geophysical Monograph.

Thyng, K. M., Greene, C. A., Hetland, R. D., Zimmerle, H. M., \& DiMarco, S. F. (2016). True colors of oceanography: Guidelines for effective and accurate colormap selection. Oceanography, 29. https://doi.org/10.5670/oceanog.2016.66

Tintoré, J., Gomis, D., Alonso, S., \& Parrilla, G. (1991). Mesoscale dynamics and vertical motion in the Alboran Sea. Journal of Physical Oceanography, 21(6), 811-823.

Troupin, C., Beltran, J. P., Heslop, E., Torner, M., Garau, B., Allen, J., et al. (2015). A toolbox for glider data processing and management. Methods in Oceanography, 13-14, 13-23. http://www.sciencedirect.com/science/article/pii/S2211122015300207

Troupin, C., Pascual, A., Ruiz, S., Olita, A., Casas, B., Margirier, F., et al. (2019). The AlborEx dataset: Sampling of sub-mesoscale features in the Alboran Sea. Earth System Science Data, 11(1), 129-145. https://www.earth-syst-sci-data.net/11/129/2019/

Viúdez, A., \& Claret, M. (2009). Numerical simulations of submesoscale balanced vertical velocity forcing unsteady nutrient-phytoplankton-zooplankton distributions. Journal of Geophysical Research, 114, C04023. https://doi.org/10.1029/2008JC005172

Viúdez, Álvaro, Tintoré, J., \& Haney, R. L. (1996). Circulation in the alboran sea as determined by quasi-synoptic hydrographic observations. Part I: Three-dimensional structure of the two anticyclonic gyres. Journal of Physical Oceanography, 26(5), 684-705. https://doi.org/10.1175/1520-0485(1996)026<0684:CITASA $>2.0 . \mathrm{CO} ; 2$

Zielinski, O., Llinás, O., Oschlies, A., \& Reuter, R. (2002). Underwater light field and its effect on a one-dimensional ecosystem model at station ESTOC, north of the Canary Islands. Deep Sea Research Part II: Topical Studies in Oceanography, 49(17), 3529-3542. http://www. sciencedirect.com/science/article/pii/S0967064502000966 